\title{
Synthesis and characterization of starch sulfates obtained by the sulfamic acid-urea complex
}

\author{
Feride Akman ${ }^{1}$, Alexandr S. Kazachenko ${ }^{2 *}$ 0000-0002-3121-1666', Natalya Yu. \\ Vasilyeva $^{2,3}$, Yuriy N. Malyar ${ }^{2,3}$ 0000-0001-9380-0290 \\ ${ }^{1}$ University of Bingöl, Vocational School of Technical Sciences, 12000 Bingöl, Turkey \\ ${ }^{2}$ Institute of Chemistry and Chemical Technology SB RAS, Federal Research Center "Krasnoyarsk \\ Science Center SB RAS", Akademgorodok, 50/24, Krasnoyarsk, 660036, Russia \\ ${ }^{3}$ Siberian Federal University, Svobodny av., 79, Krasnoyarsk, 660041, Russia
}

*Corresponding author, Aleksandr Kazachenko e-mail: leo_lion_leo@mail.ru Received [Dates will be filled in by the Editorial office] 


\begin{abstract}
The process of solid-phase sulfation of starch with sulfamic acid in the presence of urea was studied. The sulfur content of starch sulfate increases with increasing sulfation temperature from 70 to $100^{\circ} \mathrm{C}$. To obtain starch sulfates with a high sulfur content (about 10 wt.\%), It is advisable to carry out the sulfation process at a temperature of $100^{\circ} \mathrm{C}$ for 120 minutes. Mathematical modeling of the process of solid-phase sulfation of starch with sulfamic acid in the presence of urea was carried out. The introduction of a sulfate group in the structure of starch is confirmed by FTIR spectroscopy. In the FTIR spectra of sulfated starch, in contrast to the original starch, there are absorption bands at $1255 \mathrm{~cm}^{-1}, 808-817 \mathrm{~cm}^{-1}$ and 859-867 $\mathrm{cm}^{-1}$, corresponding to sulfate groups. Solid-phase sulfation of starch with a complex of sulfamic acid - urea can improve the environmental safety and efficiency of the process in comparison with the known methods of sulfation. Initial starch and sulfated starch were analyzed by gel permeation chromatography. The initial starch was shown to have a main peak with Mn $139 \mathrm{kDa}$ and $\mathrm{Mw} 382 \mathrm{kDa}$, and sulfated starch has a peak in the chromatogram relating to $\mathrm{Mn} 44 \mathrm{kDa}$ and $\mathrm{Mw} 60 \mathrm{kDa}$. Besides, the quantum chemical calculations of the starch and sulfated starches (in dimer forms) formed when different number of hydroxyl groups in starch were replaced with sulfate groups were performed using the DFT/B3LYP method with $6-31+G(d, p)$ basis set in the ground state. Firstly, these molecules were optimized. Then, from the optimized geometry of the starch and sulfated starches, frontier molecular orbitals (FMOs), molecular electrostatic potential (MEP) surfaces, bond parameters, chemical reactivity descriptors such as chemical potential, electron affinity, electronegativity, ionization energy, electrophilicity index and chemical hardness have been calculated theoretically. In addition, spectroscopic analyzes of starch and sulfated starches such as FTIR and ${ }^{1} \mathrm{H}$ NMR were theoretically performed using the same method and compared with each other.
\end{abstract}

Keywords: starch, sulfation, sulfamic acid, sulfated starch, DFT, HOMO-LUMO, MEP solidphase synthesis, structure. 


\section{Introduction}

Polysaccharides are the most abundant polymer on Earth. They are present in both plants, animals and microorganisms. Polysaccharides are long-chain polymers of mono-, diand oligosugars linked by glycosidic bonds [1,2]. It is known that the introduction of a sulfate group in the structure of a polysaccharide can give them anticoagulant, antioxidant, antiviral and anti-inflammatory activity [1].

Due to their biological activity, sulfated polysaccharides are increasingly being studied as antithrombotic agents and anticoagulants as an alternative to heparin. Heparin is actively used in clinical practice. It is obtained from raw materials of animal origin, however, it can cause negative side effects on the human body and be a source of pathogenic microflora [3].

Polysaccharides can be chemically modified with sulfate groups, which can improve and also give them new biological properties. The biological activity of sulfated polysaccharides also depends on their molecular weight [3,4]. Complexes of sulfuric anhydride with various basic reagents have been widely used for sulfating polysaccharides. This method is widely used with minor modifications to sulfate many carbohydrates and related compounds [3,5-8].

Among the many polysaccharides, starch is widely used - a polymer consisting of glucose units connected by glycosidic bonds [9]. In industry, starch is used as a thickener, viscogen, binding agent and carrier of active substances. Chemical modification of starch by sulfate groups can enhance the biological activity, giving it anticoagulant, hypolipidemic and antiviral properties [10]. It was shown in [11,12] that with increasing sulfur content in starch sulfate, its anticoagulant activity increases. Sulfated starch also can be used as a plasticizer for hydraulic binders, thermoset food adhesives, protective colloids, a thickener for food products and drilling fluids, coatings for paper and textiles [13].

Currently, there are several methods for producing sulfated starch. Traditionally, starch sulfates are produced using highly hydrolytic sulfating agents, such as sulfuric acid, chlorosulfonic acid and sulfur trioxide [14-16]. The use of these sulfating agents can lead to hydrolysis or decomposition of starch chains during the $[17,18]$. To reduce the hydrolytic or degrading effect, various organic solvents, such as pyridine, dimethyl sulfoxide, triethylamine, toluene, or ethylene dichloride, was used as the reaction medium [19-22]. Thus, it becomes relevant to develop starch sulfation methods using more environmentally friendly methods without the use of toxic solvents. 
The aim of this work was an environmentally more secure solid-state synthesis of starch sulfates using the sulfamic acid-urea complex and their study by FTIR spectroscopy, DFT method, and gel permeation chromatography.

\section{Experimental}

As the source of raw materials are used potato starch (LLC "Nsk-st").

Sulfation of starch was carried out by the sulfamic acid-urea complex according to a modified procedure [23]. To do this, the sulfating complex (SC) and starch were triturated to obtain a homogeneous mass. Sulphating complex was obtained by preliminary mixing $7.2 \mathrm{~g}$ of sulfamic acid $(75 \mathrm{mmol})$ and $4.5 \mathrm{~g}$ of urea $(75 \mathrm{mmol})$. The ratio of starch and sulfating complex was 1: 3 (mol/ mol). The resulting reaction mixture was thermostated with constant stirring and at temperatures of $70,80,90$ and $100^{\circ} \mathrm{C}$, with a process duration of 30, 60, 120 and 180 minutes. In this temperature range, the reaction mass melted.

At the end of the thermostating process, the melt was cooled to room temperature, the formed solid product was dissolved in $50 \mathrm{ml}$ of water, the unreacted sulfamic acid was neutralized with a $10 \%$ aqueous sodium hydroxide solution to $\mathrm{pH} 7-8$. The resulting solution was evaporated to a volume of 10-15 $\mathrm{ml}$ in vacuum of a water-jet pump.

Purification of the sodium salt of sulfated starch was carried out by dialysis on cellophane against distilled water. The product was dialyzed for 10 hours, changing the water at intervals of 1-2 hours.

The FTIR spectra of initial starch and sulfated starch were recorded using a Tensor-27 FTIR spectrometer (Bruker, Germany) within the wavelength range of $400-4000 \mathrm{~cm}^{-1}$. The spectral information was analysed using the OPUS program (version 5.0). Solid samples for analysis were prepared in the form of pills in a KBr matrix (2 mg sample/1000 mg KBr).

The average molecular weight (Mw), average molecular mass (Mn) and polydispersity of sulfated starch samples were defined by gel permeation chromatography using an Agilent 1260 Infinity II Multi-Detector GPC/SEC System chromatograph with triple detection: by a refractometer (RI), by a viscometer (VS) and by a light scattering (LS). The separation was made on two Aquagel-OH Mixed-M columns using the solution $0.2 \mathrm{MNaNO}_{3}+$ $0,01 \mathrm{MNaH}_{2} \mathrm{PO}_{4}$ in water $(\mathrm{pH}=7)$ as the mobile phase. The column was calibrated using polydisperse polyethylene glycol standards (Agilent, USA). The feed rate of the eluent was 1 $\mathrm{ml} / \mathrm{min}$, the volume of the used sample was $100 \mu \mathrm{l}$. Before analysis, the samples were dissolved in the mobile phase $(1 \mathrm{mg} / \mathrm{ml})$ and filtered through a $0.45 \mu \mathrm{m}$ PTFE membrane 
filter (Millipore). Data collection and data processing were performed using Agilent GPC / SEC MDS software.

Elemental analysis of sulfated starch was performed on a FlashEA-1112 elemental analyzer (ThermoQuest, Italia).

Calculation of kinetic data was performed as described in [24]. The numerical optimization of the starch sulfation process with sulfamic acid was carried out using the Statgraphics Centurion XVI software, according to the procedure described in [25].

\section{Computational methods}

The quantum chemical calculations have been performed to optimize the starch (a) and sulfated starches such as Sulfated Starch (b) (C7 and C17), Sulfated Starch (c) (C6,C7 and C16,C17) and Sulfated Starch (d) (C1,C6,C7 and C11,C16,C17) (in dimer forms) using Density Functional Theories (DFT)/B3LYP which is Becke's [26] three parameter hybrid exchange functional with Lee-Yang-Parr correlation functional [27] method with 6-31+G (d,p) basis set using Gaussian $09 \mathrm{~W}$ software [28]. The HOMO and LUMO plots, MEP and contour maps and the optimized molecular structures were visualized using GaussView 05 program [29]. Also, the chemical shifts ( ${ }^{1} \mathrm{H}$ NMR) which were calculated using the GIAO (gauge-including atomic orbital) method [30,31] using $\mathrm{D}_{2} \mathrm{O}$ solvent, electronic properties, molecular structure parameters and vibrational frequencies of the the starch and sulfated starches (in dimer form) were calculated.

\section{Results and discussion}

1. Features of the process of solid-phase sulfation of starch with sulfamic acid-urea complex

Starch sulfation reaction with sulfamic acid-urea complex and the subsequent isolation of starch sulfate in the sodium salt form was carried out according to the scheme:

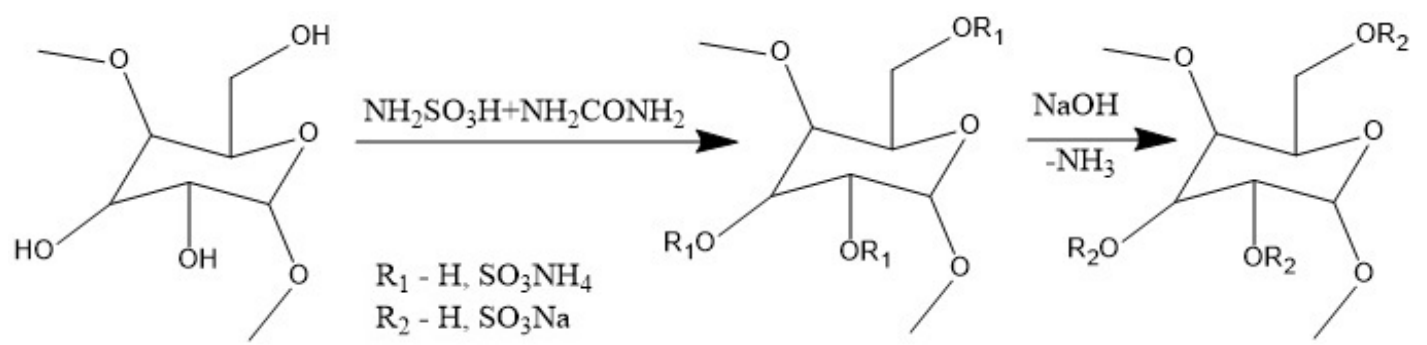

The mechanism of sulfation of polysaccharides by sulfamic acid is not well understood. However, it is assumed [32-35] that upon alcohols sulfation reaction proceeds by 
the first order for sulfamic acid and zero order for alcohol. This shows that the limiting stage is some kind of transformation in the acid molecule, possibly its decomposition into ammonia and sulfur trioxide:

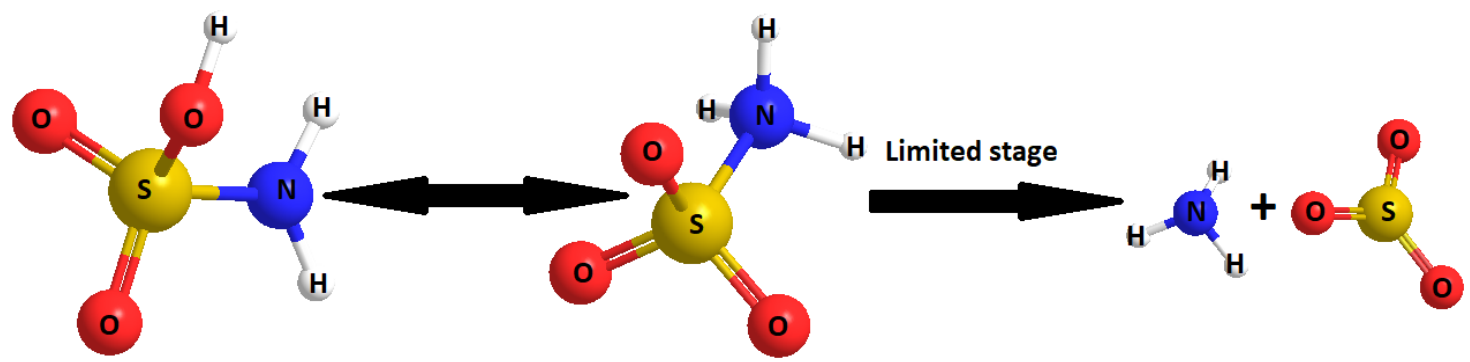

The increase in the reactivity of sulfamic acid in the presence of the main catalysts is explained by the formation of a donor - acceptor complex with a higher sulfation reactivity $[32,33]$. The rate of direct interaction of alcohols with sulfamic acid is lower than the rate of catalyzed sulfation, because the $\mathrm{S}-\mathrm{N}$ bond in sulfamic acid is stronger than in the donor acceptor complex [33].

In the study of starch sulfation by sulfamic acid the time and temperature of the process were varied. Data on the sulfur content in starch sulfate obtained under these experimental conditions is shown in table 1.

Table 1 Sulfur content of starch sulfate obtained by sulfamic acid-urea complex

\begin{tabular}{|c|c|c|c|}
\hline № & Temperature, ${ }^{\circ} \mathrm{C}$ & Time, min & $\begin{array}{c}\text { Sulfur content, } \\
\text { mas. \% }\end{array}$ \\
\hline 1 & 70 & 30 & 0,1 \\
2 & 70 & 60 & 0,2 \\
3 & 70 & 120 & 0,4 \\
4 & 70 & 180 & 0,8 \\
5 & 80 & 30 & 1,5 \\
6 & 80 & 60 & 2,7 \\
7 & 80 & 120 & 3,9 \\
8 & 80 & 180 & 5,1 \\
9 & 90 & 30 & 3,4 \\
10 & 90 & 60 & 4,4 \\
11 & 90 & 120 & 6,9 \\
12 & 90 & 180 & 8,3 \\
13 & 100 & 60 & 7,7 \\
14 & 100 & 120 & 9,1 \\
15 & 100 & 180 & 10,1 \\
16 & 100 & & 10,3 \\
& & 60 &
\end{tabular}

It was found that the sulfur content in sulfated starch can be controlled by varying the temperature and duration of the sulfation process (Table 1). The maximum sulfur content was 
observed at a process temperature of $100^{\circ} \mathrm{C}$ and the time of process of 120 minutes. A further increase in the time of the process does not significantly affect the sulfur content in sulfated starch.

\section{Kinetics of starch sulfation process}

The kinetics of the starch sulfation process with a mixture of sulfamic acid - urea was studied in the temperature range $70-100{ }^{\circ} \mathrm{C}$. It was found that the starch sulfation process at all temperatures is satisfactorily described by a first-order equation (Fig. 1).

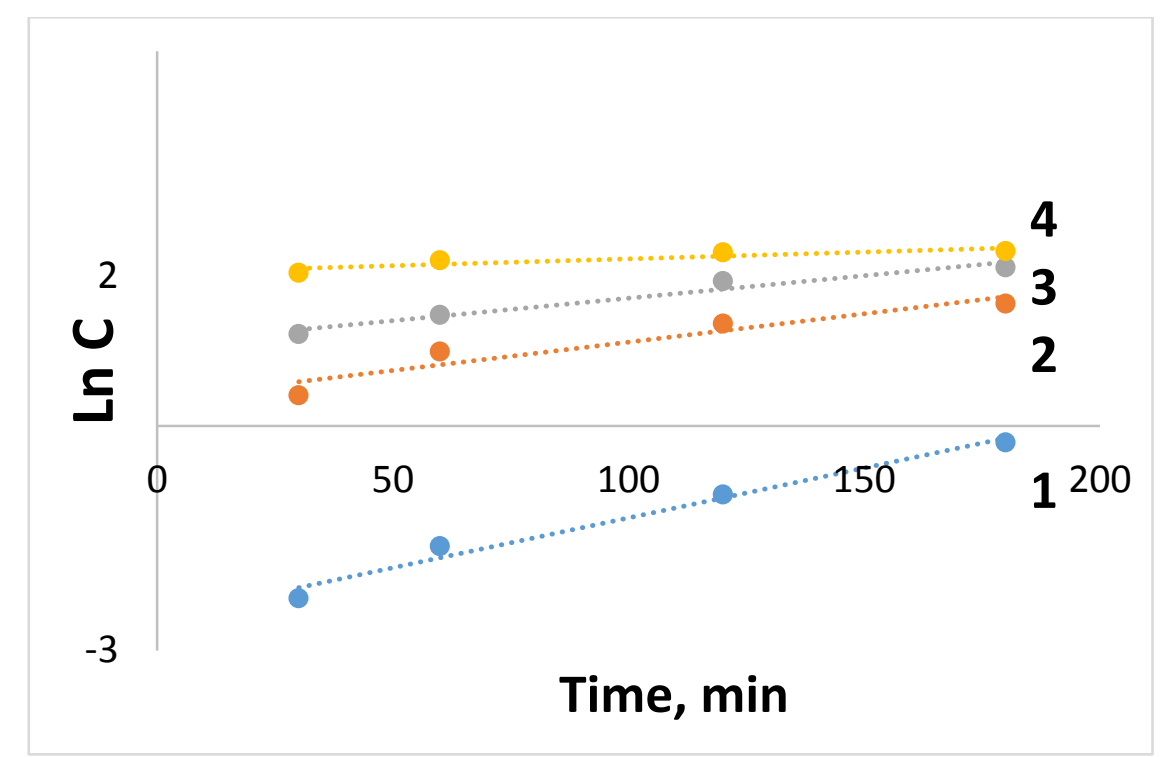

Fig. 1. Dependence of the logarithm of the sulfur content in sulfated starch (Ln C) on the duration of the sulfation process $\left(1-70^{\circ} \mathrm{C}, 2-80^{\circ} \mathrm{C}, 3-90^{\circ} \mathrm{C}, 4-100^{\circ} \mathrm{C}\right)$

The rate constants of the starch sulfation process were calculated from the change in sulfur content in sulfated starch. The activation energy of the sulfation process was determined from the temperature dependence of the rate constants in the Arrhenius coordinates (Fig. 2). 


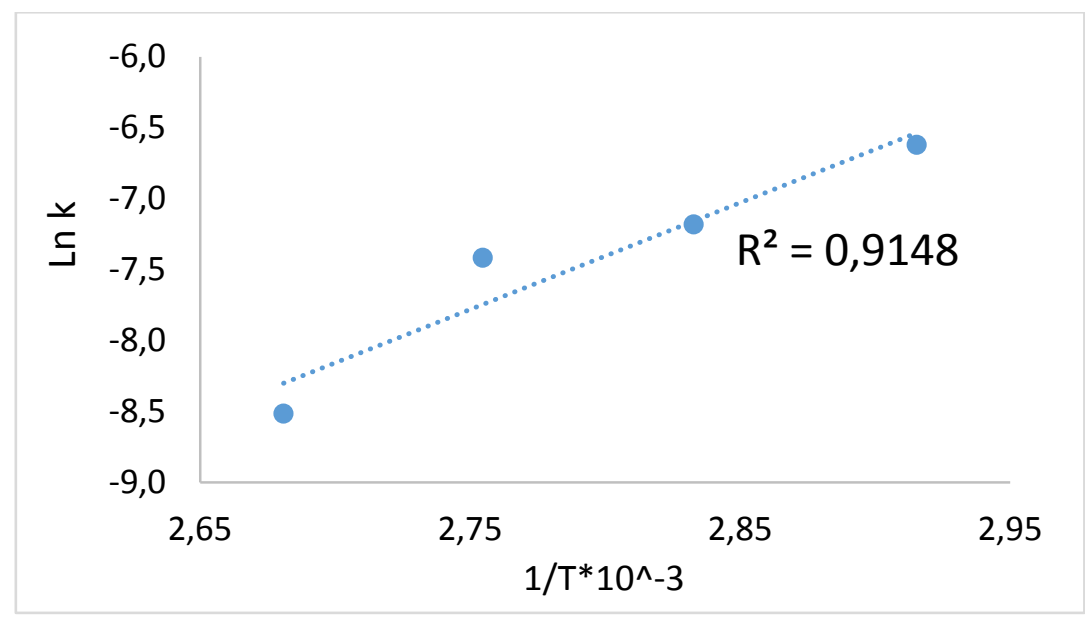

Fig. 2. Temperature dependence of the rate constants of starch sulfation process

As follows from the obtained results, the value of activation energy $\left(E_{a}\right)$ for the process of solid-phase starch sulfation by sulfamic acid in the presence of urea is $64.1 \mathrm{~kJ} / \mathrm{mol}$.

\section{Mathematical optimization of starch sulfation process}

The aim of optimizing the sulfation process is to search for conditions that provide sulfated starch with a maximum sulfur content. The independent variables were used following factors: temperature $\left(\mathrm{X}_{1}\right)$ and the duration of sulphation process $\left(\mathrm{X}_{2}\right)$. The result of the sulfation process was characterized by the output parameter as the sulfur content in sulfated starch $\left(\mathrm{Y}_{1}\right)$.

Analysis of variance and mathematical modeling were performed for the output parameter $\left(\mathrm{Y}_{1}\right)$ of the starch sulfation process.

High prognostic properties of the mathematical model are also observed if it is implemented using the sulfur content in the sulfated starch sample as an output parameter (Table 2).

Table 2. Analysis of variance for $\mathrm{Y}_{1}$ depending on $\mathrm{X}_{1}$ and $\mathrm{X}_{2}$

\begin{tabular}{|c|c|c|c|c|c|}
\hline $\begin{array}{c}\text { Variance } \\
\text { source }\end{array}$ & Sum of squares & $\begin{array}{c}\text { Number of degrees } \\
\text { of freedom }\end{array}$ & $\begin{array}{c}\text { Average } \\
\text { square }\end{array}$ & F-Ratio & P-Value \\
\hline $\mathrm{A}: \mathrm{X}_{1}$ & 51.0417 & 1 & 51.0417 & 134.88 & 0.0014 \\
\hline $\mathrm{B}: \mathrm{X}_{2}$ & 20.9067 & 1 & 20.9067 & 55.25 & 0.0050 \\
\hline $\mathrm{AA}$ & 0.0938889 & 1 & 0.0938889 & 0.25 & 0.6526 \\
\hline $\mathrm{AB}$ & 0.2025 & 1 & 0.2025 & 0.54 & 0.5174 \\
\hline $\mathrm{BB}$ & 1.74222 & 1 & 1.74222 & 4.60 & 0.1212 \\
\hline
\end{tabular}


Analysis of variance showed that, within the limits of the accepted experimental conditions, the factor $\mathrm{X}_{1}$ makes a significant contribution to the total dispersion. This is indicated by the high values of the dispersion relations $\mathrm{F}$, also called influence efficiencies. The influence of the dispersion source on the output parameter is considered statistically significant if the significance level is $\mathrm{P}<0.05$, corresponding to a confidence level of $95 \%$.

The influence of factors $\mathrm{X}_{1}$ and $\mathrm{X}_{2}$ on the sulfur content $\left(\mathrm{Y}_{1}\right)$ in sulfated starch is described by the regression equation:

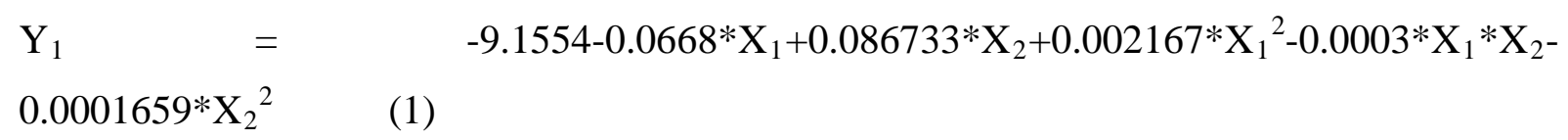

The values of the output parameter $\mathrm{Y}_{1}$ were compared with the values predicted by equation (1) (Fig. 3). The straight line corresponds to the calculated (predicted) values of Y1. The proximity of most "experimental points" to the straight line indicates that the selected model has good prognostic properties of the regression equations.

Plot of S

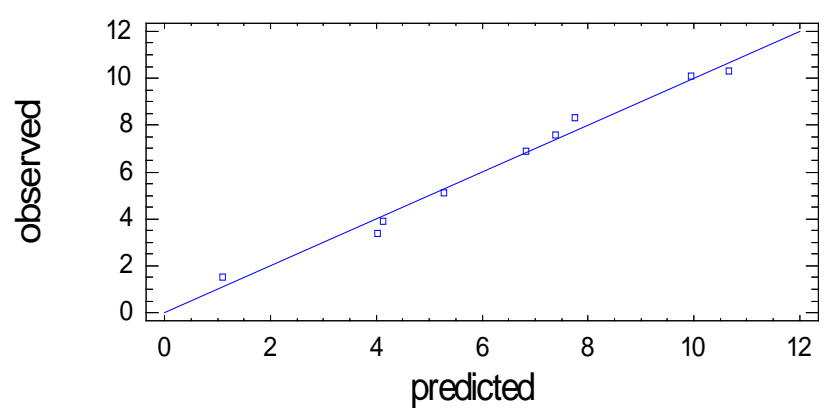

Fig. 3. Comparison of experimental and calculated values of sulfur content in sulfated starch during sulfation with varying time of process and temperature

Figure 4 shows the response surface of the output parameter $\mathrm{Y}_{1}$ (sulfur content) temperature $\left(\mathrm{X}_{1}\right)$ and the time of the sulfation process $\left(\mathrm{X}_{2}\right)$.

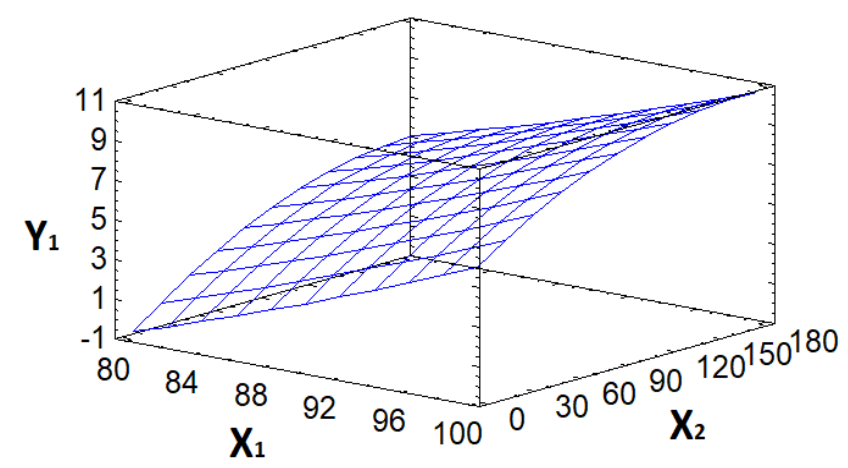


Fig. 4. The response surface of the output parameter $Y_{1}$ (sulfur content) and variable factors - $\mathrm{X}_{1}$ and $\mathrm{X}_{2}$

The optimal conditions for the starch sulfates obtaining with a maximum sulfur content $(10.3 \% \mathrm{wt})$ are the process temperature of $99^{\circ} \mathrm{C}$ and a duration of 119 minutes.

\section{The study of the structure of sulfated starch}

\subsection{FTIR spectroscopy}

The inclusion of the sulfate group in the structure of starch was confirmed by FTIR spectroscopy (Fig. 5).

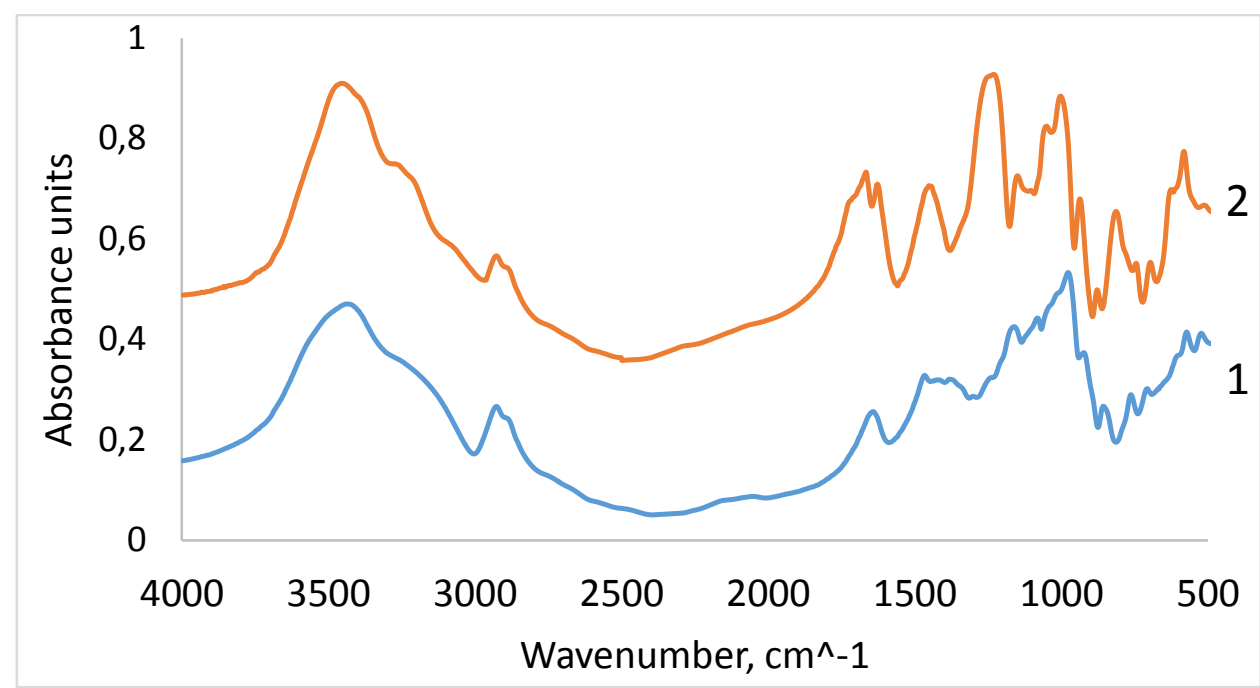

Fig.5. FTIR spectra of potato starch (1) and sodium salt of sulfated starch (2)

In the FTIR spectra of sulfated starch, in contrast to the original starch, there is a highintensity band at $1255 \mathrm{~cm}^{-1}$, which belongs to asymmetric stretching vibrations $v_{\text {as }}(\mathrm{O}=\mathrm{S}=\mathrm{O})$. The presence of absorption bands at $808-817 \mathrm{~cm}^{-1}$ and $859-867 \mathrm{~cm}^{-1}$, which are absent in the FTIR spectrum of the initial starch, indicates the presence of primary and secondary sulfates of the sodium salt of starch (Fig. 5), which is consistent with the data presented in the works [36-38].

\subsection{GPC analysis of sulfated starch}

According to gel permeation chromatography (Fig.6,7), the initial starch has the main peak with Mn $139 \mathrm{kDa}$ and $\mathrm{Mw} 382 \mathrm{kDa}$, and the molecular weight spread is quite large, individual molecules probably have a mass of more than $3000 \mathrm{kDa}$. Also in the sample there 
is some admixture of oligosaccharides with a mass of about $1-2 \mathrm{kDa}$, probably formed as a result of partial hydrolysis of starch. In a sample of sulfated starch, the molecular weight distribution pattern changes significantly.

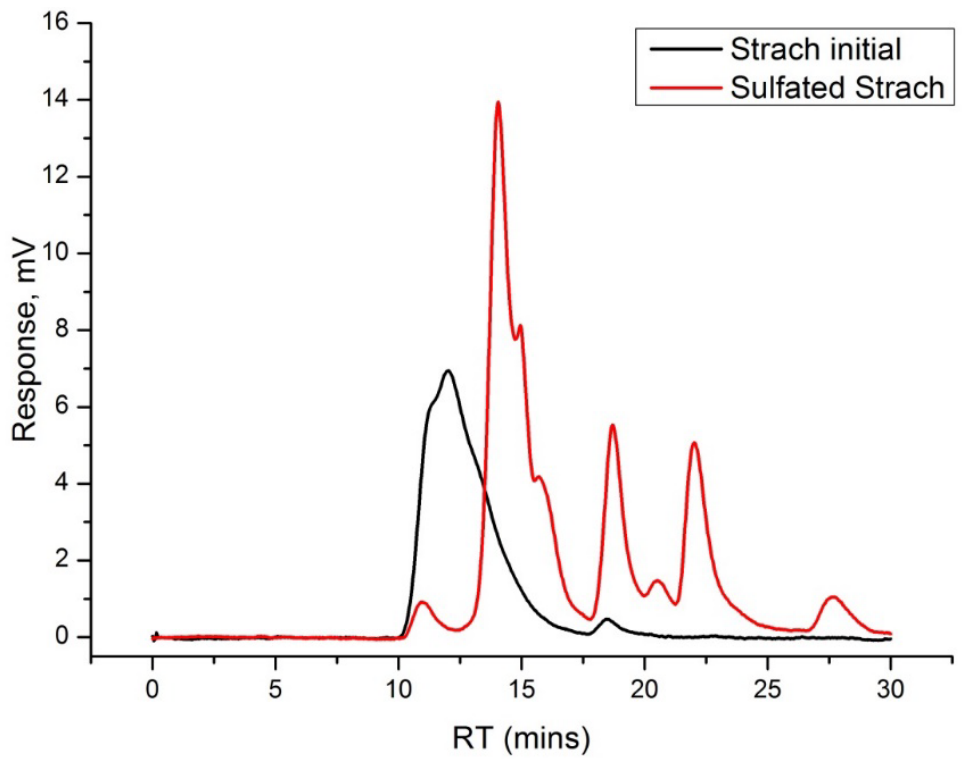

Fig. 6. Gel chromatogram of starch and sulfated starch samples

The peak with maximum mass (RT 11min) most likely belongs to unreacted initial starch (Fig.6). The main peak with $\mathrm{Mn} 44 \mathrm{kDa}$ and $\mathrm{Mw} 60 \mathrm{kDa}$ refers to the target product. Moreover, in this area, three peaks can be distinguished, which can correspond to individual products of joint destruction and sulfation.

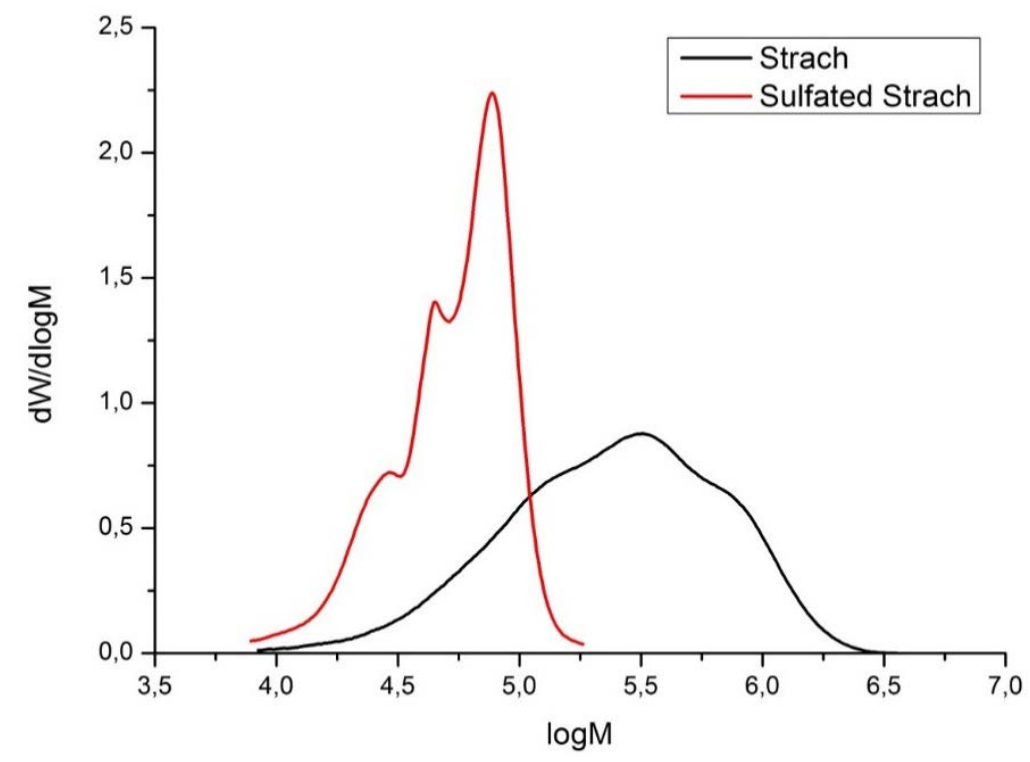

Fig.7. Curves of molecular weight distribution of the main peaks (samples of the initial starch and sulfated starch)

Also, this molecular weight distribution may indicate some fractionation of starch and probably different reactivity of individual sections of starch chains (Fig.7). The remaining 
peaks with a release time of more than 17 minutes and a mass of less than $1 \mathrm{kDa}$ relate to low molecular weight decomposition products of starch and their interaction with sulfamic acid and urea.

\section{DFT calculation of starch sulfate}

\subsection{Molecular geometry}

The first task for a computational study is to determine the optimized geometry of the molecule. Therefore, the optimized geometry of starch and sulfated starches were calculated using the B3LYP/6-31+G (d,p) method. The optimized molecular geometry in conformity with the atomic labeling of starch (a) and sulfated starches (b-d) are shown in Fig. 8.

(a)

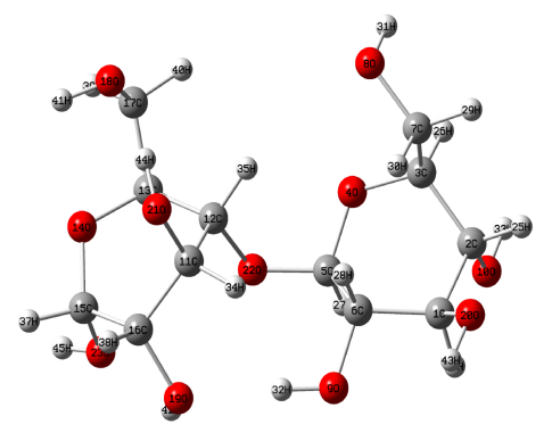

(b)

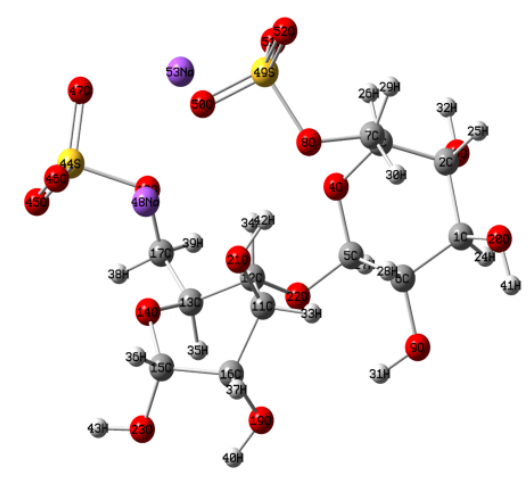

(c)

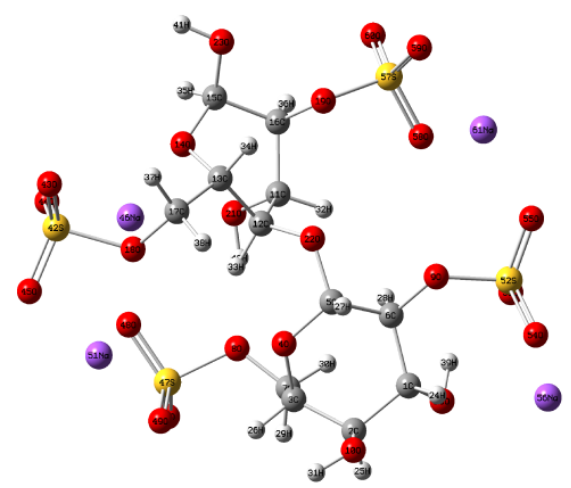

(d)

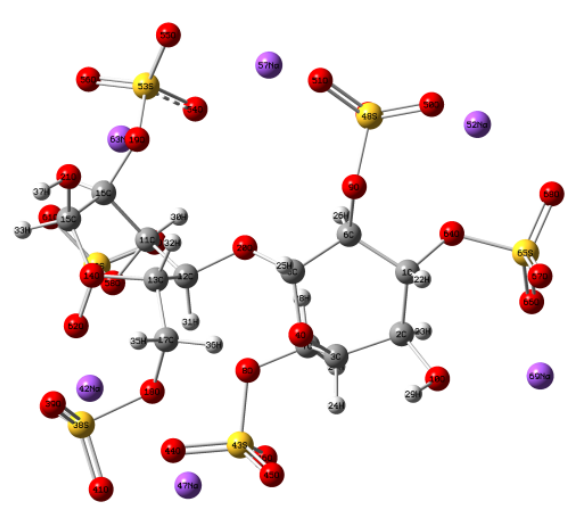

Fig. 8. The Optimized geometrical structures of starch (a), sulfated starch (b) sulfated starch (c) and sulfated starch (d) using B3LYP/6-31+G(d,p) level of theory.

The optimized structural parameters such as bond lengths and bond angles of starch and sulfated starches (b-d) are given in Table 3.

Table 3. Optimized bond lengths $(\AA)$ and bond angles $\left({ }^{\circ}\right)$ of starch and sulfated starch (C7 and C17) in gaseous phase 


\begin{tabular}{|c|c|c|c|}
\hline Parameters & Starch (a) & Parameters & $\begin{array}{l}\text { Sulfated Starch (b) } \\
\text { (C7 and C17) }\end{array}$ \\
\hline \multicolumn{4}{|c|}{ Bond Lengths $(\AA)$} \\
\hline C1-C2 & 1.5393 & C1-C2 & 1.5444 \\
\hline C1-C6 & 1.5347 & C1-C6 & 1.5313 \\
\hline C1-O20 & 1.4283 & C1-O20 & 1.4278 \\
\hline C1-H24 & 1.0965 & C1-H24 & 1.0965 \\
\hline C2-C3 & 1.5374 & C2-C3 & 1.538 \\
\hline C2-OO10 & 1.4323 & C2-O10 & 1.4285 \\
\hline C2-H25 & 1.0981 & C2-H25 & 1.0989 \\
\hline C3-O4 & 1.4326 & C3-O4 & 1.4371 \\
\hline C3-C7 & 1.539 & C3-C7 & 1.5503 \\
\hline C3-H26 & 1.1029 & C3-H26 & 1.0936 \\
\hline O4-C5 & 1.4257 & O4-C5 & 1.4127 \\
\hline C5-C6 & 1.5361 & C5-C6 & 1.5319 \\
\hline C5-O22 & 1.4094 & C5-O22 & 1.4266 \\
\hline C5-H27 & 1.0961 & C5-H27 & 1.0966 \\
\hline C6-O9 & 1.4152 & C6-O9 & 1.4186 \\
\hline C6-H28 & 1.0992 & C6-H28 & 1.0973 \\
\hline C7-O8 & 1.4225 & C7-O8 & 1.4421 \\
\hline C7-H29 & 1.1006 & C7-H29 & 1.0954 \\
\hline C7-H30 & 1.0911 & C7-H30 & 1.0915 \\
\hline O8-H31 & 0.9665 & O8-S49 & 1.6875 \\
\hline O9-H32 & 0.9789 & O9-H31 & 0.9705 \\
\hline O10-H33 & 0.9664 & O10-H32 & 0.9668 \\
\hline C11-C12 & 1.5389 & C11-C12 & 1.5563 \\
\hline C11-C16 & 1.5442 & C11-C16 & 1.5299 \\
\hline C11-O21 & 1.4195 & C11-O21 & 1.4378 \\
\hline C11-H34 & 1.0935 & C11-H33 & 1.0927 \\
\hline C12-C13 & 1.5519 & C12-C13 & 1.5429 \\
\hline C12-O22 & 1.4406 & C12-O22 & 1.4293 \\
\hline C12-H35 & 1.0948 & C12-H34 & 1.0905 \\
\hline C13-O14 & 1.4454 & C13-O14 & 1.4454 \\
\hline C13-C17 & 1.5271 & C13-C17 & 1.5211 \\
\hline C13-H36 & 1.0961 & C13-H35 & 1.0957 \\
\hline O14-C15 & 1.4116 & O14-C15 & 1.4195 \\
\hline C15-C16 & 1.5614 & O14-O45 & 3.9865 \\
\hline C15-O23 & 1.4156 & C15-C16 & 1.5499 \\
\hline C15-H37 & 1.0943 & C15-O23 & 1.4083 \\
\hline C16-O19 & 1.4299 & C15-H36 & 1.0953 \\
\hline C16-H38 & 1.0944 & C16-O19 & 1.419 \\
\hline C17-O18 & 1.4321 & C16-H37 & 1.0983 \\
\hline C17-H39 & 1.0968 & C17-O18 & 1.4439 \\
\hline C17-H40 & 1.0929 & C17-H38 & 1.0926 \\
\hline O18-H41 & 0.968 & C17-H39 & 1.0947 \\
\hline O19-H42 & 0.9714 & O18-S44 & 1.7546 \\
\hline O20-H43 & 0.9677 & O19-H40 & 0.9693 \\
\hline O21-H44 & 0.9755 & $\mathrm{O} 20-\mathrm{H} 41$ & 0.9677 \\
\hline \multirow[t]{10}{*}{ O23-H45 } & 0.9659 & O21-H42 & 0.9761 \\
\hline & & O23-H43 & 0.9675 \\
\hline & & S44-O45 & 1.4611 \\
\hline & & S44-O46 & 1.4855 \\
\hline & & S44-O47 & 1.4862 \\
\hline & & O46-Na48 & 2.2666 \\
\hline & & S49-O50 & 1.4982 \\
\hline & & S49-O51 & 1.4938 \\
\hline & & S49-O52 & 1.4577 \\
\hline & & O51-Na53 & 2.291 \\
\hline \multicolumn{4}{|c|}{ Bond Angles $\left({ }^{\circ}\right)$} \\
\hline C2-C1-C6 & 112.585 & C2-C1-C6 & 112.1097 \\
\hline
\end{tabular}




\begin{tabular}{|c|c|c|c|}
\hline C2-C1-O20 & 107.9775 & C2-C1-O20 & 108.0115 \\
\hline C2-C1-H24 & 106.8697 & C2-C1-H24 & 106.9825 \\
\hline C6-C1-O20 & 111.1781 & C6-C1-O20 & 110.7535 \\
\hline C6-C1-H24 & 107.7193 & C6-C1-H24 & 108.3123 \\
\hline O20-C1-H24 & 110.4328 & O20-C1-H24 & 110.617 \\
\hline C1-C2-C3 & 112.8948 & C1-C2-C3 & 112.8118 \\
\hline C1-C2-O10 & 105.6116 & C1-C2-O10 & 105.7784 \\
\hline C1-C2-H25 & 107.7448 & C1-C2-H25 & 107.4446 \\
\hline C3-C2-OO10 & 110.6737 & C3-C2-O10 & 110.7748 \\
\hline C3-C2-H25 & 109.3214 & C3-C2-H25 & 109.2199 \\
\hline O10-C2-H25 & 110.5134 & O10-C2-H25 & 110.7349 \\
\hline C2-C3-O4 & 112.4272 & C2-C3-O4 & 111.8038 \\
\hline C2-C3-C7 & 112.9615 & C2-C3-C7 & 111.3221 \\
\hline C2-C3-H26 & 107.6824 & C2-C3-H26 & 109.3469 \\
\hline O4-C3-C7 & 112.1402 & O4-C3-C7 & 113.3378 \\
\hline O4-С3-H26 & 104.2719 & O4-C3-H26 & 103.3053 \\
\hline C7-C3-H26 & 106.6987 & C7-C3-H26 & 107.2572 \\
\hline C3-O4-C5 & 118.9941 & C3-O4-C5 & 119.3473 \\
\hline O4-C5-C6 & 111.343 & O4-C5-C6 & 112.1888 \\
\hline O4-C5-O22 & 108.0437 & O4-C5-O22 & 110.0167 \\
\hline O4-C5-H27 & 110.1606 & O4-C5-H27 & 109.9062 \\
\hline C6-C5-O22 & 113.8316 & C6-C5-O22 & 111.2545 \\
\hline C6-C5-H27 & 109.5638 & C6-C5-H27 & 109.4985 \\
\hline O22-C5-H27 & 103.6109 & O22-C5-H27 & 103.6359 \\
\hline C1-C6-C5 & 110.4641 & C1-C6-C5 & 111.1458 \\
\hline C1-C6-O9 & 106.9902 & C1-C6-O9 & 108.0765 \\
\hline C1-C6-H28 & 107.7097 & C1-C6-H28 & 107.5691 \\
\hline C5-C6-O9 & 112.4914 & C5-C6-O9 & 111.2659 \\
\hline C5-C6-H28 & 108.3802 & C5-C6-H28 & 108.8633 \\
\hline O9-C6-H28 & 110.7056 & O9-C6-H28 & 109.8464 \\
\hline C3-C7-O8 & 112.6453 & C3-C7-O8 & 112.2187 \\
\hline С3-С7-H29 & 108.3248 & C3-C7-H29 & 109.4742 \\
\hline С3-С7-Н30 & 111.6301 & С3-С7-H30 & 112.4622 \\
\hline O8-C7-H29 & 111.1407 & O8-C7-H29 & 110.0415 \\
\hline О8-С7-Н30 & 105.6548 & O8-C7-Н30 & 105.008 \\
\hline Н29-С7-Н30 & 107.3294 & Н29-С7-Н30 & 107.4599 \\
\hline C7-O8-H31 & 109.3834 & C7-O8-S49 & 117.7638 \\
\hline C6-O9-H32 & 110.533 & C6-O9-H31 & 108.4185 \\
\hline C2-O10-H33 & 109.3737 & C2-O10-H32 & 109.5012 \\
\hline C12-C11-C16 & 111.5171 & C12-C11-C16 & 112.6369 \\
\hline C12-C11-O21 & 112.0876 & C12-C11-O21 & 109.5675 \\
\hline C12-C11-Н34 & 109.5565 & C12-C11-Н33 & 110.0035 \\
\hline C16-C11-O21 & 110.6291 & C16-C11-O21 & 107.487 \\
\hline C16-C11-H34 & 106.0482 & C16-C11-H33 & 107.271 \\
\hline O21-C11-H34 & 106.7032 & O21-C11-H33 & 109.8034 \\
\hline C11-C12-C13 & 110.845 & C11-C12-C13 & 110.8643 \\
\hline C11-C12-O22 & 111.4664 & C11-C12-O22 & 115.3729 \\
\hline C11-C12-H35 & 109.7795 & C11-C12-H34 & 106.5149 \\
\hline C13-C12-O22 & 105.557 & C13-C12-O22 & 105.5587 \\
\hline C13-C12-Н35 & 109.7096 & C13-C12-Н34 & 109.9309 \\
\hline O22-C12-H35 & 109.3955 & O22-C12-H34 & 108.5569 \\
\hline C12-C13-O14 & 113.2036 & C12-C13-O14 & 108.8061 \\
\hline C12-C13-C17 & 114.2454 & C12-C13-C17 & 113.8295 \\
\hline C12-C13-Н36 & 106.6299 & C12-C13-H35 & 108.676 \\
\hline O14-C13-C17 & 104.4099 & O14-C13-C17 & 107.3149 \\
\hline O14-C13-Н36 & 109.4734 & O14-C13-H35 & 109.7828 \\
\hline C17-C13-Н36 & 108.7983 & C17-C13-H35 & 108.386 \\
\hline C13-O14-C15 & 117.5159 & C13-O14-C15 & 114.6585 \\
\hline O14-C15-C16 & 112.3548 & C13-O14-O45 & 83.274 \\
\hline O14-C15-O23 & 111.9747 & C15-O14-O45 & 153.4961 \\
\hline
\end{tabular}




\begin{tabular}{|c|c|c|c|}
\hline O14-C15-H37 & 103.6555 & O14-C15-C16 & 112.5525 \\
\hline C16-C15-O23 & 107.9968 & O14-C15-O23 & 112.0583 \\
\hline C16-C15-Н37 & 110.705 & O14-C15-Н36 & 104.3043 \\
\hline O23-C15-H37 & 110.1394 & C16-C15-O23 & 107.1331 \\
\hline C11-C16-C15 & 112.0609 & С16-С15-Н36 & 110.3033 \\
\hline C11-C16-O19 & 110.215 & O23-C15-H36 & 110.5307 \\
\hline C11-C16-H38 & 106.3737 & C11-C16-C15 & 109.7571 \\
\hline C15-C16-O19 & 112.3996 & C11-C16-O19 & 106.0237 \\
\hline С15-С16-Н38 & 108.0018 & C11-C16-H37 & 109.3298 \\
\hline O19-С16-H38 & 107.4741 & C15-C16-O19 & 112.9173 \\
\hline C13-C17-O18 & 112.1486 & C15-C16-H37 & 108.226 \\
\hline C13-C17-H39 & 109.5232 & O19-C16-H37 & 110.5399 \\
\hline C13-C17-H40 & 109.7464 & C13-C17-O18 & 110.9423 \\
\hline O18-C17-H39 & 109.9681 & C13-C17-H38 & 110.8098 \\
\hline O18-C17-H40 & 106.735 & С13-C17-H39 & 109.0298 \\
\hline Н39-C17-H40 & 108.6289 & O18-C17-H38 & 109.1304 \\
\hline C17-O18-H41 & 107.138 & O18-C17-H39 & 107.8921 \\
\hline C16-O19-H42 & 107.5934 & Н38-С17-Н39 & 108.9676 \\
\hline C1-O20-H43 & 107.5653 & C17-O18-S44 & 118.8977 \\
\hline C11-O21-H44 & 110.7435 & C16-O19-H40 & 108.0867 \\
\hline C5-O22-C12 & 119.6042 & C1-O20-H41 & 107.9778 \\
\hline \multirow[t]{18}{*}{ C15-O23-H45 } & 109.5559 & C11-O21-H42 & 107.4257 \\
\hline & & C5-O22-C12 & 119.3832 \\
\hline & & C15-O23-H43 & 109.3681 \\
\hline & & O18-S44-O45 & 106.3444 \\
\hline & & O18-S44-O46 & 101.7765 \\
\hline & & O18-S44-O47 & 98.0455 \\
\hline & & O45-S44-O46 & 116.5704 \\
\hline & & O45-S44-O47 & 117.13 \\
\hline & & O46-S44-O47 & 113.4212 \\
\hline & & O14-O45-S44 & 65.286 \\
\hline & & S44-O46-Na48 & 108.4143 \\
\hline & & O8-S49-O50 & 99.5548 \\
\hline & & O8-S49-O51 & 105.4434 \\
\hline & & O8-S49-O52 & 106.5802 \\
\hline & & O50-S49-O51 & 110.1408 \\
\hline & & O50-S49-O52 & 116.8299 \\
\hline & & O51-S49-O52 & 116.1642 \\
\hline & & S49-O51-Na53 & 98.4662 \\
\hline
\end{tabular}

As seen from Table 3, the calculated bond lengths value of starch (a) are between 0.96 and $1.56 \AA$, whereas the bond lengths value of sulfated starch (b) are between 0.96 and 2.29 A. In starch and sulfated starch, C15-C16 and O51-Na53 are the longest bonds, while O23H45 and O10-H32 are the shortest bonds, respectively. C7-O8 and C17-O18 bond lengths in starch are calculated as 1.4225 and $1.4321 \AA$, whereas these bond lengths in sulfated starch are 1.4421 and $1.4439 \AA$. The shortening of bonding distance by sulfation can be explained by the fact that the atomic size of the sulfur is larger than hydrogen.

The calculated bond angles value of starch are between 103.61 and $119.60^{\circ}$, whereas the bond angles value of sulfated starch are between 65.28 and $119.38^{\circ}$. In starch and sulfated starch, C5-O22-C12 are the largest bond angles, while O22-C5-H27 and O14-O45-S44 are 
the smallest bond angles, respectively. In starch, C5-O22-C12 with $119.60^{\circ}$ bond angle decreased to $119.38^{\circ}$ by sulfation. In starch by sulfation, C3-O4-C5 with $118.99^{\circ}$ bond angle increased to $119.34^{\circ}$, whereas C13-O14-C15 with $117.51^{\circ}$ bond angle decreased to $114.65^{\circ}$.

\subsection{Molecular electrostatic potential}

The MEP is as a significant tool and its surface maps can be can be used to visualize charge distributions and charge dependent properties and to predict the electrophilic and nucleophilic attack regions of molecules [39,40]. The MEP surfaces of starch (a) and sulfated starches (b-d) were determined using the B3LYP/6-31+G (d,p) method used in optimization of molecules. The designated three-dimensional surface maps are shown in Fig. 9.

(a)

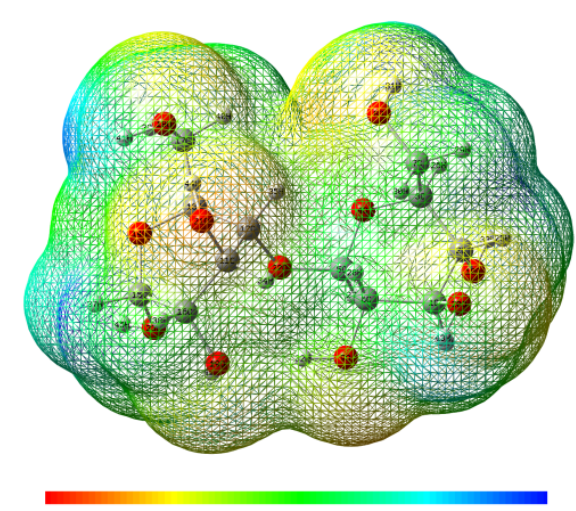

(b)

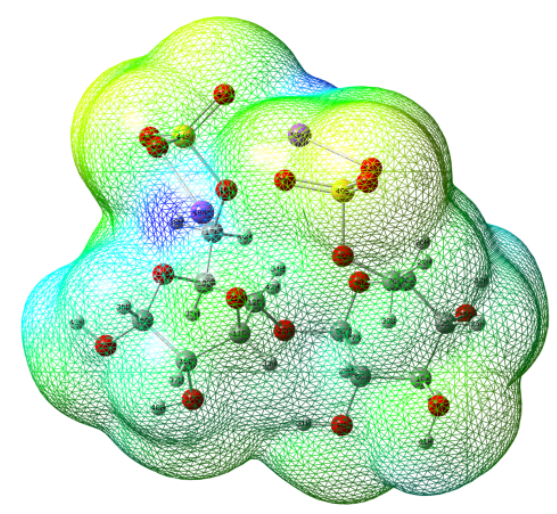

(c)

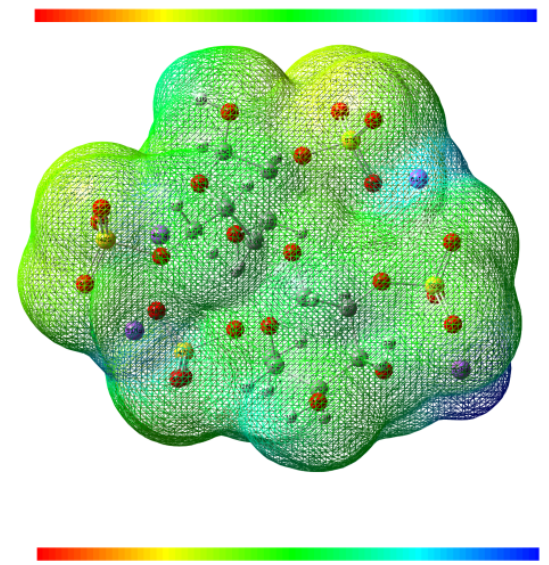

(d)

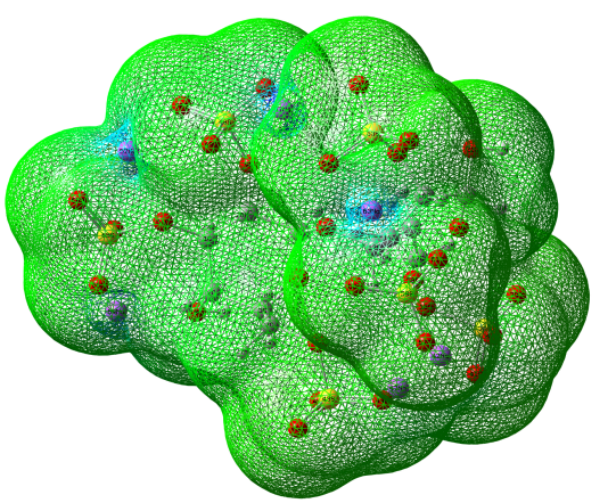

Fig. 9. Molecular electrostatic potential energy surface maps of starch (a), sulfated starch (b) sulfated starch (c) and sulfated starch (d) using B3LYP/6-31+G(d,p) level of theory.

In MEP analysis, the reactive regions can be seen with different color codes due to the color order of the electrostatic potential such as red < orange <yellow < green <blue. The blue color in the MEP maps represents the electron deficient region, which is the positive electrostatic potential, while the red color indicates the electron rich region, which is the 
negative electrostatic potential. Besides, the green color in the MEP maps indicates the neutral region which is zero electrostatic potential.

As shown in Fig. 9 (a), the hydrogen atoms attached to oxygens have the lowest electron density and are shown as blue color on the map, while the electron density of the oxygen atoms is higher and is seen as reddish yellow. We noticed that the some changes in the MEP maps with the sulfation of starch. Looking at Fig. 9 (b-d), as the hydrogen atoms attached to the oxygen are sulfated, the blue color on the map is gradually diminished over hydrogen atoms due to the depletion of acidic hydrogens in starch molecule and finally positioned over the sodium atoms. Similarly, as the hydrogen atoms attached to the oxygen are sulfated, the electron density on oxygen atoms decreased and reddish yellow color shifted to green. Contour maps of MEP are drawn on the molecular plane and used to show electrostatic potential with constant density or bright lines. The contour maps of starch and sulfated starchs are demonstrated in Fig.10.

(a)

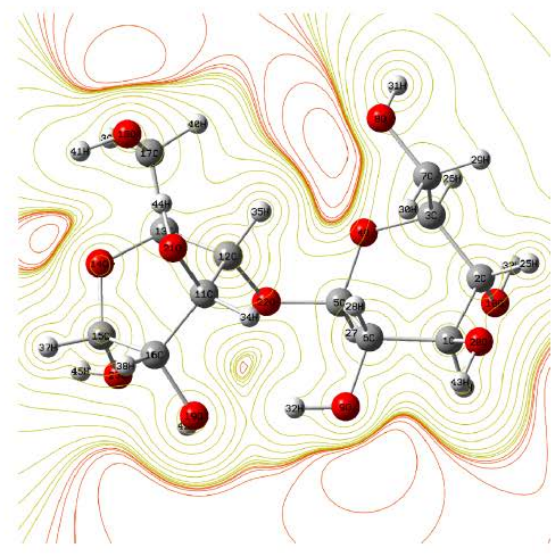

(b)

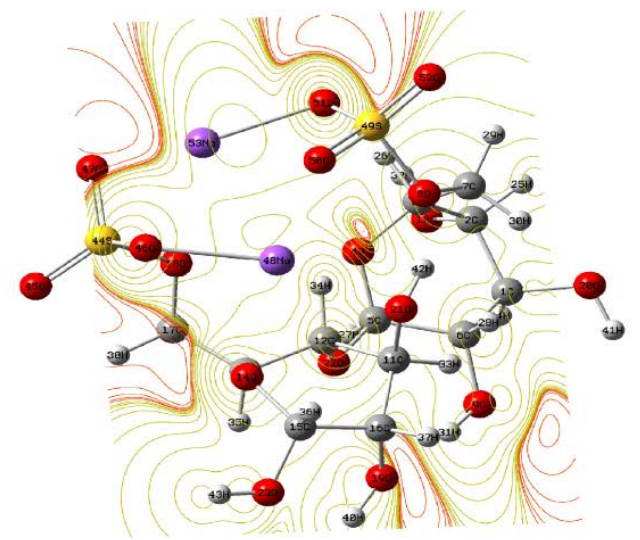

(c)

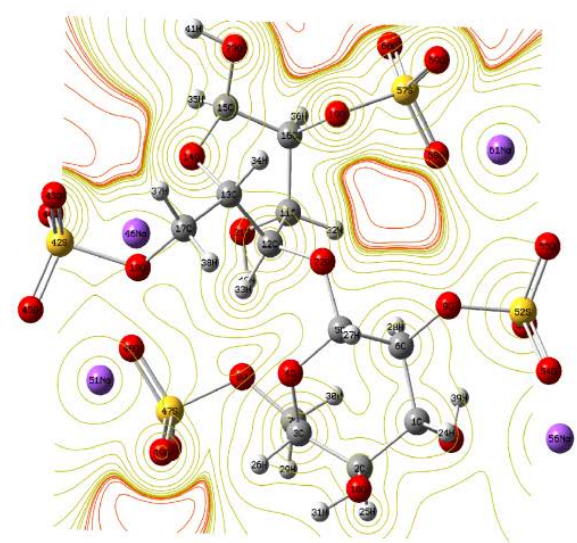

(d)

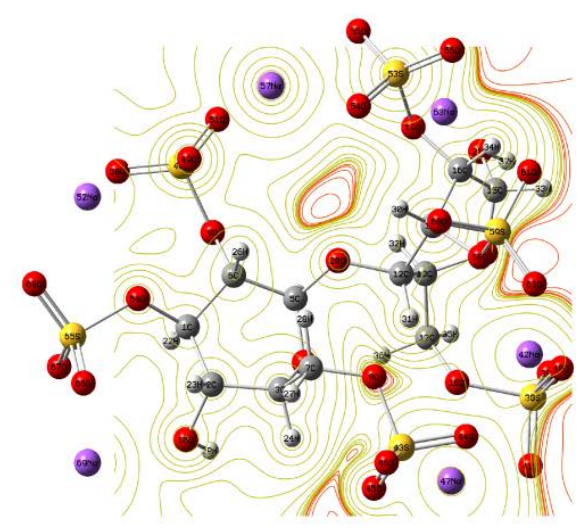

Fig. 10. The contour map of Molecular electrostatic potential surface of starch (a), sulfated starch (b) sulfated starch (c) and sulfated starch (d) using B3LYP/6-31+G(d,p) level of theory. 
As shown in Fig.3, the contour maps of starch and sulfated starch demonstrate positive and negative potential regions relative to molecular electrostatic potential surfaces $[41,42]$. Here, yellowish lines which are electron-deficient zones or positive potential zones, while red lines are electron-rich zones or negative potential zones.

\subsection{Frontier molecular orbital analysis}

Frontier Molecular orbitals (HOMO and LUMO) and their energies ( $\mathrm{E}_{\text {Hомо }}$ and $\mathrm{E}_{\mathrm{LUMO}}$ ) are very important for scientists, especially chemists and physicists, as in quantum chemistry. HOMO ( Highest Occupied Molecular Orbital ) and LUMO (Lowest Unoccupied Molecular Orbital ) are called as Frontier molecular orbital (FMOs) because they can determine how the molecule interacts with other species. HOMO can be identified as a nucleophile that gives an electron that acts as an electron donor, while LUMO can be defined as an electrophile that receives an electron from the nucleophile that acts as an electron acceptor [43]. A molecule having a small energy gap means highly polarized and mostly associated with high chemical reactivity and low kinetic stability. Graphs of frontier molecular orbitals (HOMO and LUMO) of starch (a) and sulfated starches (b-d) were calculated by the B3LYP/6-31+G (d,p) method used in the optaimization of molecules and are shown in Fig.11.

LUMO

(First Excited State)

(a)
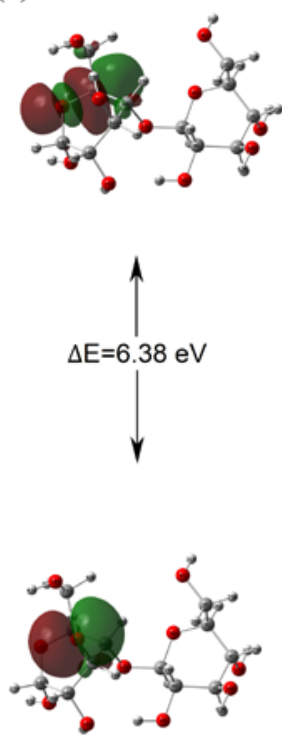

(b)
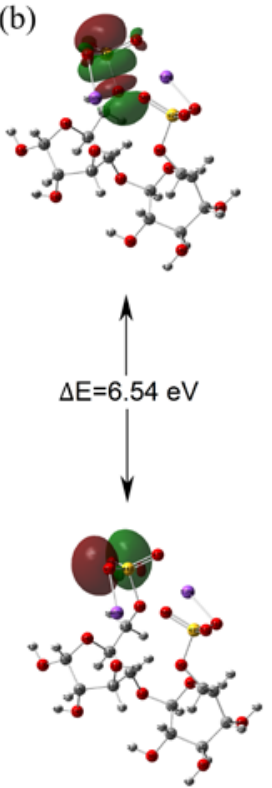

(c)
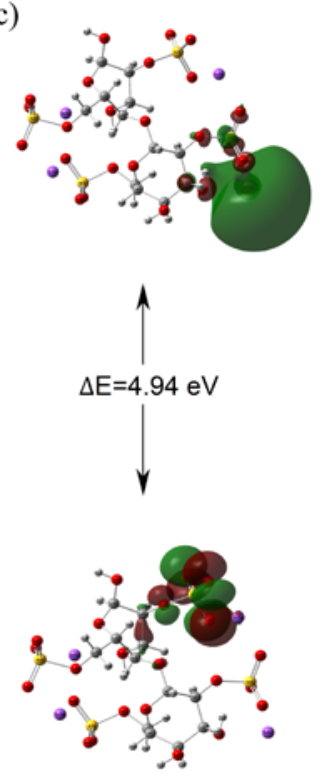

(Ground State)
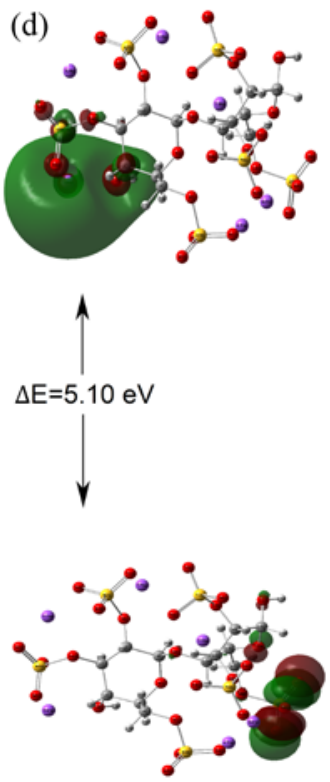
Fig. 11. Frontier molecular orbital (HOMO and LUMO) plots of starch (a), sulfated starch (b) sulfated starch (c) and sulfated starch (d) using B3LYP/6-31+G(d,p) level of theory.

As shown in Fig.11, HOMO and LUMO have nodes and are symmetrically located. Red is the positive phase, while green is the negative phase. Energy gap (Egap), Electronegativity $(\chi)$, electron affinity (EA), chemical potential ( $\mu$ ), ionization potential (IP), hardness $(\eta)$, softness $(\varsigma)$, and electrophilicity index (ळ) of starch and sulfated starches have been determined by using HOMO and LUMO energies and these descriptors can be calculated by the following equations [44,45]:

Energy

gap

(Egap); $E_{g a p}=$

$E_{\text {LUMO }}-E_{\text {HOMO }}$

(2)

Electronegativity;

$\chi=$

$-1 / 2\left(E_{\text {LUMO }}+E_{\text {номо }}\right)$

(3)

Electron

affinity; $E A=-E_{L U M O}$

(4)

Chemical

potential;

$\mu$

$=$

$1 / 2\left(E_{\text {LUMO }}+E_{\text {номо }}\right)$

(5)

Ionization

potential;

$I P=-E_{\text {номо }}$

(6)

Hardness;

$\eta=$

$1 / 2\left(E_{\text {LUмо }}-E_{\text {номо }}\right)$

Softness;

$$
\varsigma=\frac{1}{\eta}
$$

(8)

Electrophilicity

index;

$$
\omega=\frac{\mu^{2}}{2 \eta}
$$

(9)

The values of calculated descriptors are given in Table 4 .

Table 4. Some electronic properties for starch and sulfated starches

\begin{tabular}{llllc}
\hline Parameters (eV) & Starch $(\mathbf{a})$ & $\begin{array}{l}\text { Sulfated Starch } \\
\text { (b) }(\mathbf{C 7} \text { and } \mathbf{C 1 7})\end{array}$ & $\begin{array}{l}\text { Sulfated Starch } \\
\text { (c) (C6,C7 and } \\
\text { C16,C17) }\end{array}$ & $\begin{array}{l}\text { Sulfated Starch (d) } \\
\text { (C1,C6,C7 and } \\
\text { C11,C16,C17 }\end{array}$ \\
\hline $\mathrm{E}_{\mathrm{HOMO}}$ & & & -7.1748 & -7.2583 \\
$\mathrm{E}_{\mathrm{LUMO}}$ & -6.8950 & -7.5283 & -2.2302 & -2.1507 \\
Energy Band Gap $\left[\Delta \mathrm{E}=\mathrm{E}_{\mathrm{LUMO}}-\mathrm{E}_{\mathrm{HOMO}}\right]$ & -0.5064 & -0.9809 & 4.9445 & 5.1076
\end{tabular}




Electrophilicity index $(\omega)$
Softness $(\varsigma)$
Ionization energy $(I)$
Chemical potential $\left(\mu_{o}\right)$
Dipole Moment $(\mu)$
Electron affinity $(A)$
Electronegativity $(\chi)$
Chemical hardness $(\eta)$
SCF Energy

As seen in Table 4, the chemical potential of starch and sulphated starches are negative values, ie the molecules are stable. In other words, they do not spontaneously decompose into elements. Hardness indicates the resistance of chemical systems to deformation of the electron cloud during chemical processing [46]. Hard systems having a large HOMO-LUMO energy gap are much less polarizable and relatively small, while soft systems having a small HOMO-LUMO energy gap are highly polarizable and large. Among the molecules studied, sulphated starch (b) has the highest energy gap and the lowest is sulphated starch (c). Sulphated starch (c) with an energy gap of $4.94 \mathrm{eV}$ is more stable than the others, which means that easily charge transfer takes place easier than others. In addition, the sulfated starch (c) among the molecules studied had the highest dipole moment with a value of $17.25 \mathrm{D}$. As a result we can say that, the sulfated starch (c) is more polarizable than others and as the dipole moment is increased, the intermolecular interactions will increase.

\subsection{Theoretical FTIR Analysis}

The vibrational analysis for starch and sulfated starches were carried out by using DFT with B3LYP functional having extended $6-31+G(d, p)$ basis set. The calculated vibrational wavenumbers are generally higher than relevant experimental values due to the deficiencies of basis sets, electron correlation effects and calculations performed in the gaseous phase. Therefore, we used the scaling factor to match the theoretical results with the experimental data. The calculated frequencies are scaled by 0.9613 for DFT/B3LYP/6-31+G (d,p) computation [47]. The calculated FTIR spectra of starch and sulfated starches are shown in Fig. 12. 


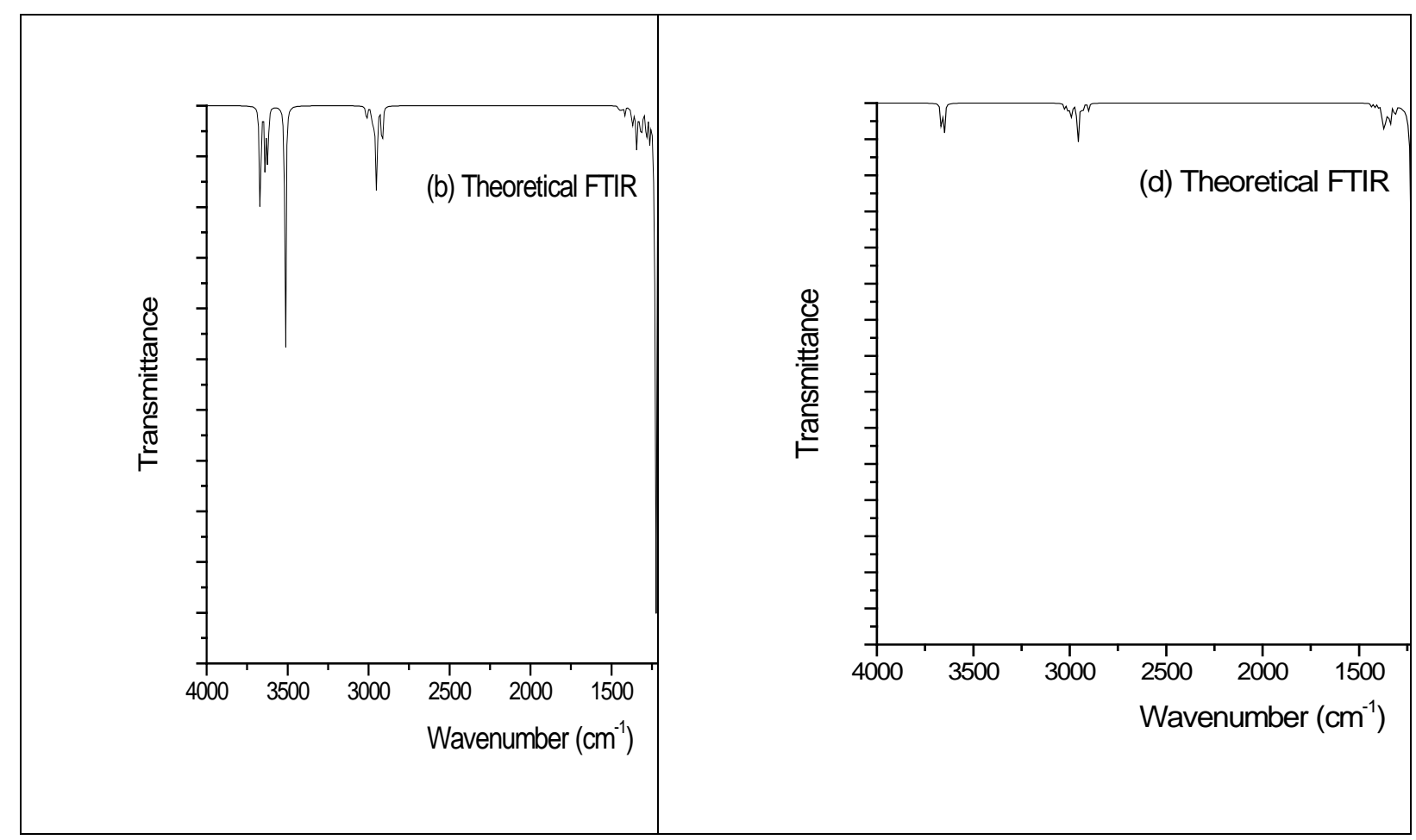

Fig. 12. The theoretical FTIR spectra of starch (a), sulfated starch (b), sulfated starch (c )and sulfated starch (d )using B3LYP/6-31+G(d,p) level of theory.

The selected important wavenumbers for sulfated starch are given Table 5. The theoretical FTIR spectra of starch (a) show that bands in the range of 3689-3446 $\mathrm{cm}^{-1}$ were related to -OH stretching vibrations which directly connected to the rings, while the bands at 3667 and $3661 \mathrm{~cm}^{-1}$ were related to $-\mathrm{OH}$ stretching vibrations adjacent to $-\mathrm{CH}_{2}$ groups. The bands in the range of $3016-2860 \mathrm{~cm}^{-1}$ were related to $-\mathrm{CH}$ stretching vibrations. The bands at 1441 and $1442 \mathrm{~cm}^{-1}$ are related to the bending vibrations of $-\mathrm{CH}_{2}$ groups adjacent to $-\mathrm{OH}$. The band at $1126 \mathrm{~cm}^{-1}$ is related to the stretching vibrations of -COC. The theoretical FTIR spectra of sulfated starches (b-d) show that from b to d, as the hydroxyl groups are sulfated, the vibration bands of hydroxyl group gradually disappear and the signals of the sulfate groups arise. The bands in vicinity of $1201-1191 \mathrm{~cm}^{-1}$ are related to the asymmetric stretching vibrations of sulfate groups. As a result, the theoretical results are compatible with the experimental values.

Table 3. Selected important wavenumbers for sulfated starch as theroretically and experimentally

\begin{tabular}{lll}
\hline Major Assignments & & Vibrational Frequencies $\left.\mathbf{~ ( c m}^{-\mathbf{1}}\right)$ \\
\hline & Theoretical & Experimental \\
\hline v O-H stretching (connected to ring) & $3689-3446$ & $3701-3381$ \\
$v$ O-H stretching (connected to $\left.-\mathrm{CH}_{2}\right)$ & 3667 and 3661 & İn area 3701-3600* \\
$v$ C-H stretching & $3016-2860$ & $3006-2830$
\end{tabular}


$v \mathrm{CH}_{2}$ ( connected to $-\mathrm{OH}$ ) stretching 1441 and 1442

$\checkmark$ C-O-C stretching

1126

1201 and 1191
1467 and 1423

1150

1231

* - In this area, superposition of $\mathrm{OH}$ peaks of $v \mathrm{O}-\mathrm{H}$ stretching (connected to ring) and $v$ O-H stretching (connected to $-\mathrm{CH}_{2}$ )

\subsection{Theoretical NMR Analysis}

The theoretical chemical shifts for starch and sulfated starches were calculated by B3LYP method using 6-31+G (d,p) basis set with GIAO approach. The chemical shifts of ${ }^{1} \mathrm{H}$ NMR for starch (a) and sulfated starches(b-d) are listed in the Table 4. The ${ }^{1} \mathrm{H}$ NMR spectrum of starch (a) and sulfated starches(b-d) are shown in Fig. 13.

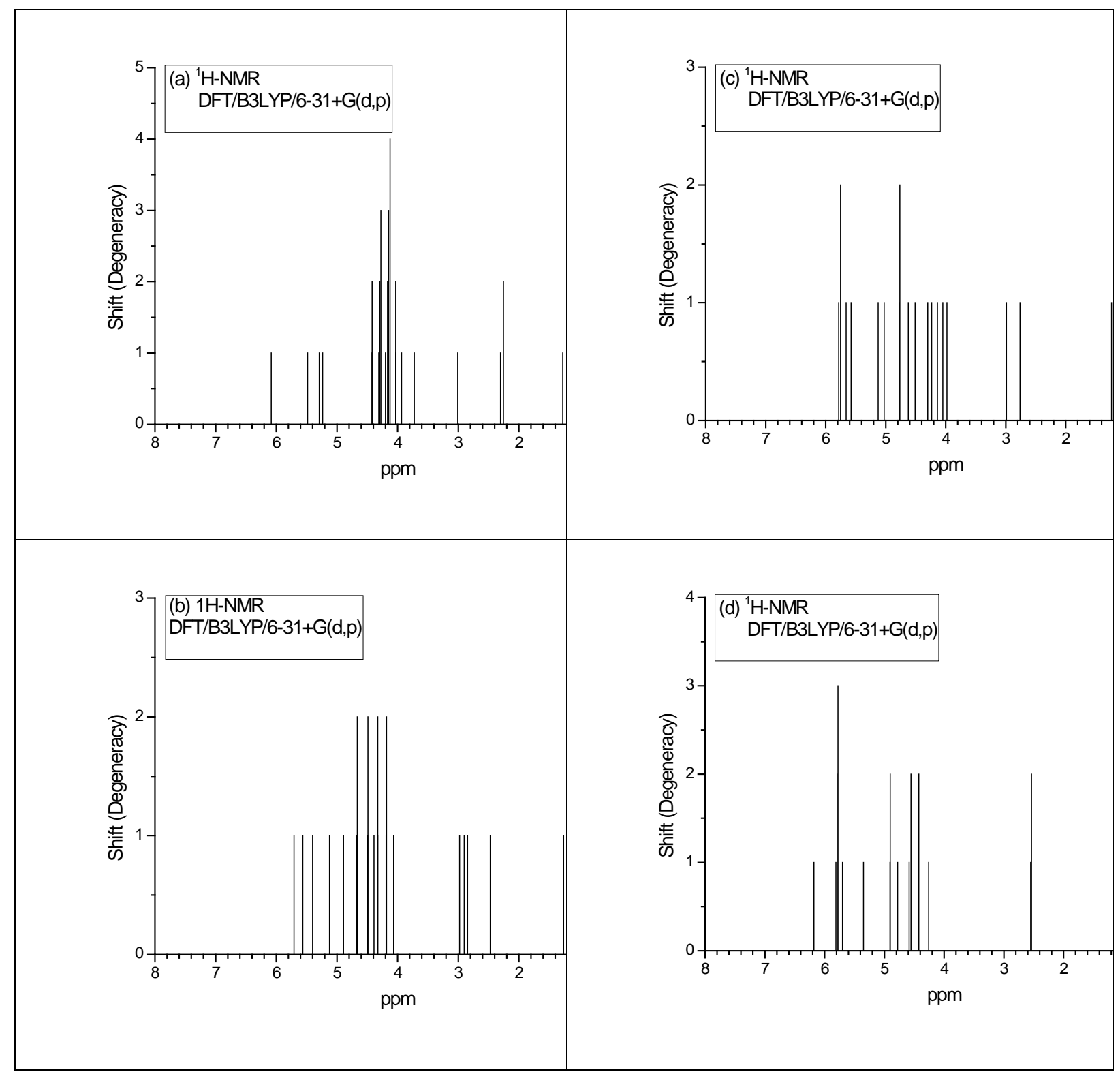


Figure 13. The theoretical ${ }^{1} \mathrm{H}$ NMR spectrum of starch (a), sulfated starch (b), sulfated starch (c )and sulfated starch (d )using B3LYP/6-31+G(d,p) level of theory.

As seen in Table 5, the hydrogens attached to $\mathrm{O} 8$ and $\mathrm{O} 18$ labeled atoms in starch (a) were disappeared by sulfation and the signals of the other hydrogens were altered in by the effect of sulfate group. In the same way, as the sulphation rate increases, the other hydrogens will disappear, as shown in Table 6.

Table 6. ${ }^{1} \mathrm{H}$ NMR chemical shifts for starch and sulfated starches

\begin{tabular}{|c|c|c|c|c|c|c|c|}
\hline \multirow{2}{*}{$\begin{array}{l}\text { Starch (a) } \\
\text { Atoms }\end{array}$} & \multirow[b]{2}{*}{ Values } & \multicolumn{2}{|c|}{$\begin{array}{l}\text { Sulfated Starch (b) (C7 and } \\
\text { C17) }\end{array}$} & \multicolumn{2}{|c|}{$\begin{array}{l}\text { Sulfated Starch (c) } \\
(\mathrm{C6}, \mathrm{C7} \text { and C16,C17) }\end{array}$} & \multicolumn{2}{|c|}{$\begin{array}{l}\text { Sulfated Starch (d) } \\
(\mathrm{C} 1, \mathrm{C} 6, \mathrm{C} 7 \text { and } \mathrm{C11}, \mathrm{C16}, \mathrm{C17}\end{array}$} \\
\hline & & Atoms & Values & Atoms & Values & Atoms & Values \\
\hline $37-\mathrm{H}$ & 6.0843 & $36-\mathrm{H}$ & 5.7086 & $35-\mathrm{H}$ & 5.7829 & 33-H & 6.1776 \\
\hline 27-H & 5.4848 & 34-H & 5.5626 & 33-H & 5.7514 & $31-\mathrm{H}$ & 5.8117 \\
\hline 32-H & 5.2901 & 27-H & 5.4021 & 27-H & 5.6576 & 34-H & 5.7891 \\
\hline 35-H & 5.2345 & 26-H & 5.1217 & 26-H & 5.5749 & 24-H & 5.777 \\
\hline 44-H & 4.4338 & 38-H & 4.8928 & $36-\mathrm{H}$ & 5.124 & 30-H & 5.702 \\
\hline 36-H & 4.4212 & $37-\mathrm{H}$ & 4.679 & $37-\mathrm{H}$ & 5.0268 & $25-\mathrm{H}$ & 5.3483 \\
\hline 38-H & 4.3115 & 29-H & 4.666 & 32-H & 4.7742 & $35-\mathrm{H}$ & 4.9041 \\
\hline 26-H & 4.2912 & 39-H & 4.4913 & 24-H & 4.7654 & 26-H & 4.9005 \\
\hline 39-H & 4.274 & 33-H & 4.4886 & 29-H & 4.6217 & $22-\mathrm{H}$ & 4.7789 \\
\hline 28-H & 4.1999 & $42-\mathrm{H}$ & 4.3901 & 38-H & 4.5095 & $23-\mathrm{H}$ & 4.5838 \\
\hline 25-H & 4.1637 & $35-\mathrm{H}$ & 4.3284 & $28-\mathrm{H}$ & 4.3009 & 27-H & 4.5537 \\
\hline 34-H & 4.1474 & $30-\mathrm{H}$ & 4.3256 & 34-H & 4.2326 & 28-H & 4.4304 \\
\hline 29-H & 4.123 & 28-H & 4.1889 & $25-\mathrm{H}$ & 4.1367 & 36-H & 4.4224 \\
\hline 24-H & 4.0318 & $25-\mathrm{H}$ & 4.1827 & $30-\mathrm{H}$ & 4.048 & 32-H & 4.2597 \\
\hline 30-H & 4.0313 & 24-H & 4.0666 & $40-\mathrm{H}$ & 3.9799 & 29-H & 2.5506 \\
\hline $40-\mathrm{H}$ & 3.936 & $40-\mathrm{H}$ & 2.9783 & 39-H & 2.9875 & 37-H & 2.5358 \\
\hline 42-H & 3.7251 & 43-H & 2.9002 & $41-\mathrm{H}$ & 2.7597 & & \\
\hline 45-H & 3.0093 & 31-H & 2.8464 & 31-H & 1.2352 & & \\
\hline $43-\mathrm{H}$ & 2.3038 & $41-\mathrm{H}$ & 2.4733 & & & & \\
\hline $41-\mathrm{H}$ & 2.254 & 32-H & 1.2636 & & & & \\
\hline 33-H & 1.2763 & & & & & & \\
\hline 31-H & 0.9661 & & & & & & \\
\hline
\end{tabular}

In starch, the signals of two hydrogens attached to C7 and C17 labeled atoms adjacent to oxygens are shown at 4.03 and $4.12 \mathrm{ppm}$, but; in the sulfated starch, the two hydrogens attached to these carbon atoms shifted to low-field, ie ie a high chemical shift values of 4.32 and $4.66 \mathrm{ppm}$.

\section{Conclusions}

In the work, the possibility of solid-phase starch sulfation by sulfamic acid-urea complex has been established. This method of producing starch sulfates is simpler and environmentally friendly in comparison with known methods of sulfation. 
To obtain starch sulfates with a high sulfur content (about 10 wt.\%), It is advisable to carry out the sulfation process at a temperature of $100^{\circ} \mathrm{C}$ for 120 minutes.

The value of activation energy was calculated for the process of solid-phase sulfation of starch with sulfamic acid in the presence of urea, which amounted to $64.1 \mathrm{~kJ} / \mathrm{mol}$.

Mathematical modeling of the process of solid-phase starch sulfation by sulfamic acidurea complex was carried out. The calculated conditions of the sulfation process providing the maximum sulfur content $(10.3 \% \mathrm{wt})$ in sulfated starch are the process temperature of $99^{\circ} \mathrm{C}$ and a time of 119 minutes.

The inclusion of the sulfate group in the starch structure is confirmed by FTIR spectroscopy. In the FTIR spectra of sulfated starch, in comparison with the original starch, absorption bands appear at $1255 \mathrm{~cm}^{-1}, 808-817 \mathrm{~cm}^{-1}$ and $859-867 \mathrm{~cm}^{-1}$, corresponding to vibrations of the sulfate group.

Initial starch and sulfated starch were analyzed by gel permeation chromatography. It has been shown that sulfated starch has a peak in the chromatogram relating to Mn 44kDa and Mw 60kDa.

Theoretical calculations of the starch and sulfated starches (in dimer forms) were performed using the DFT/B3LYP method with 6-31+G (d, p) basis set in the ground state. Optimized structural parameters such as bond lengths and bond angles were calculated and it was found that bond lengths and bond angles were reduced with the sulfating of starch. Nucleophilic and electrophilic attack regions of the the starch and sulfated starches were determined by molecular electrostatic potential and contour surface maps.

The HOMO and LUMO energy band gaps and other related molecular properties were computed and among the molecules studied, sulfated starch (c) with the lowest energy gap was found to be the most stable compound. Finally, FTIR and ${ }^{1} \mathrm{H}$ NMR analyzes of the starch and sulfated starches were performed and compared with each other. We hope that this study will be useful for those looking for theoretical and experimental evidence for starch and derivatives used in a variety of materials and applications.

Acknowledgements. The devices of the Krasnoyarsk Regional Centre for Collective Use of the SB RAS were used in the work. The authors are grateful to I.V. Korolkova for obtaining infrared spectra. For DFT calculations, the authors would like to thank Bingöl University for the server and Bitlis Eren University for supporting Gaussian 09W software.

Conflict of interest. There is no conflict of interest. 


\section{References}

1. C.M. Dore, das C. Faustino, M.G. Alves, L.S. Will, T.G. Costa, D.A. Sabry, L.A. de Souza Rêgo, C.M. Accardo, H.A. Rocha, L.G. Filgueira, E.L. Leite. Carbohydrate Polymers 91 (2013) 467-475. doi: 10.1016/j.carbpol.2012.07.075

2. A.H.P. Gracher, A.G. Santana, T.R. Cipriani, M. Lacomini Carbohydrate Polymers 136 (2015) 177-186. DOI: 10.1016/j.carbpol.2015.09.022

3. R.C.R. Oliveira, R.R. Almeida, T.A. Gonçalves. J Dev Drugs., 5 (2016) 3 DOI: 10.4172/2329-6631.1000166

4. A.A. Kuzhim, N.N. Drozd, M.A. Torlopov, A.V. Il'ina. Eksp Klin Farmakol 76 (2013) 20-24.

5. D. Mihai, G. Mocanu, A. Carpov. European Polymer Journal, 37(3) (2001) 541546. doi:10.1016/s0014-3057(00)00142-7

6. Y. Xu, Y. Wu, P. Sun, F. Zhang, R.J. Linhardt, A. Zhang. International Journal of Biological Macromolecules. 132 (2019) 970-977 doi:10.1016/j.ijbiomac.2019.03.213

7. G. Jiao, G. Yu, J. Zhang, H. Ewart. Marine Drugs. 9(2) (2011) 196-223. doi:10.3390/md9020196

8. H.E. Caputo, J.E. Strau, M.W. Grinsta ffChem. Soc. Rev. 48 (2019) 2338-2365. doi: 10.1039/c7cs00593h.

9. S.C. Zeeman, J. Kossmann, A.M. Smith. Annual Review of Plant Biology. 61(1) (2010) 209-234 doi: 10.1146/annurev-arplant-042809-112301.

10. D. Cui, M. Liu, L. Wu, Y. Bi. International Journal of Biological Macromolecules. 44 (2009) 294-299. DOI: 10.1016/j.ijbiomac.2009.01.003

11. N.N. Drozd, M.A. Torlopov, A.A. Kuzhim, V.A. Makarov. Eksp Klin Farmakol.75(6) (2012) 31-35.

12. A.A. Kuzhim, N.N. Drozd, M.A. Torlopov, V.A. Makarov. Hematology and Transfusiology (Rus.). 57(S3) (2012) 118-119.

13. H. Staroszczyk, M. Fiedorowicz, W.W. Zhong, P. Janas, P. Tomasik. e-Polymers, (2007). DOI:10.1515/epoly.2007.7.1.1635

14. P. Tomasik; C.H. Schilling. Adv. Carbohydr. Chem. Biochem. 59 (2004) 175-403. DOI: 10.1016/S0065-2318(04)59005-4

15. F. Schierbaum, K. Kordel. ACS Symposium Series. 77(11) (1978) 173-192. DOI: 10.1021/bk-1978-0077.ch011 
16. K.B. Guiseley. ACS Symposium Series. 77(11) (1978) 148- 162. DOI: 10.1021/bk-1978-0077.ch009

17. Tessler M. (1978) U.S.Pat.4086419

18. D.W. Lim, H.S. Whang, K.J. Yoon, S.W. Ko. J. Appl.Polym.Sci.79 (2001) 14231430. https://doi.org/10.1002/1097-4628(20010222)79:8<1423::AID-APP90>3.0.CO;2-V

19. S. Geresh, A. Mamontov, J. Weinstein. J. Biochem. Biophys. Methods. 50 (2002) 179-187. DOI: 10.1016/s0165-022x(01)00185-3

20. A.F. Cirelli, J.A. Covian. Carbohydr. Res. 190(2) (1989) 329-337. DOI: 10.1016/0008-6215(89)84137-0

21. Whistler R.L. (1970). U.S. Pat. 3507855

22. M.L. Wolfrom, B.O. Juliano. J. Am. Chem. Soc. 82 (10) (1960) 2588-2592.

23. J.A. Sirviö, J. Ukkola, H. Liimatainen. Cellulose. 26(4) (2019) 2303-2316 doi:10.1007/s10570-019-02257-8

24. G. Lenteю Deterministic kinetics in chemistry and systems biology. Springer, New York. 2015.142 p. doi:10.1007/978-3-319-15482-4

25. I.G. Sudakova, N.V. Garyntseva, O.V. Yatsenkova, B.N. Kuznetsov Optimization of aspen wood delignification by $\mathrm{H} 2 \mathrm{O} 2$ with sulfuric acid catalyst. J Sib Fed Univ Chem 6 (2013) 76-84

26. A.D. Becke. Phys. Rev. A. 38 (1988) 3098. doi:10.1103/PhysRevA.38.3098.

27. C. Lee, W. Yang, R.G. Parr. Phys. Rev. B.37 (1988) 785. doi:10.1103/PhysRevB. 37.785 .

28. M.J. Frisch, G.W. Trucks, H.B. Schlegel, G.E. Scuseria, M.A. Robb, J.R. Cheeseman, G. Scalmani, V. Barone, B. Mennucci, G.A. Petersson, et al. Gaussian, Inc., Wallingford CT. 2010.

29. R. Dennington, T. Keith and J. Millam. GaussView, Version 5, Semichem Inc., Shawnee Mission KS. 2010.

30. R. Ditchfield J. Chem. Phys. 56 (1972) 5688.

31. P. Pulay J. Am. Chem. Soc. 112 (1990) 8251

32.V.A. Volkov, V.V. Suchkov. Sulfated nonionic surfactants (Rus). NITK. 1976. 65 $\mathrm{p}$

33. N.Y. Vasil'eva, A.V. Levdansky, B.N. Kuznetsov, G.P. Skvortsova, A.S. Kazachenko, L. Djakovitch, C. Pinel. Russian Journal of Bioorganic Chemistry. 41(7) (2015) 725-731. DOI: 10.1134/S1068162015070158 
34. R.A. Al-Horani, U.R. Desai. Tetrahedron. 66(16) (2010) 2907-2918. DOI: 10.1016/j.tet.2010.02.015

35. W. Spillane, J.B. Malaubier. Chemical Reviews. 114(4) (2014) 2507-2586. https://doi.org/10.1021/cr400230c

36. D. Cui, M. Liu, R. Liang, Y. Bi. Starch/Stärke. 59 (2007) 91-98. https://doi.org/10.1002/star.200600567

37. D. Cui, M. Liu, B. Zhang, H. Gong, Y. Bi. Starch/Stärke. 63 (2011) 354-363. doi:10.1002/star.201000033

38. H. Korva, J. Kärkkäinen, K. Lappalainen, M. Lajunen. Starch/Stärke. 68(9-10) (2016) 854-863. https://doi.org/10.1002/star.201600155

39. E. Scrocco, J. Tomasi. Adv. Quant. Chem. 11 (1978) 116-193.

40. J.S. Murray, K. Sen, Molecular Electrostatic Potentials, Concepts and Applications, Elsevier, Amsterdam, The Netherlands, 1996.

41. P. Demir, F. Akman. Journal of Molecular Structure. 1134 (2017) 404-415. https://doi.org/10.1016/j.molstruc.2016.12.101

42. E. Barim, F. Akman. Journal of Molecular Structure. 1195 (2019) 506513 https://doi.org/10.1016/j.molstruc.2019.06.015

43. S. Muthu, S. Renuga, Spectrochim. Acta A $132 \quad$ (2014) 313325 https://doi.org/10.1016/j.saa.2014.05.009

44. R.G. Parr, R.A. Donnelly, M. Levy, W.E. Palke, J. Chem. Phys. 68 (1978) 38013807 https://doi.org/10.1063/1.436185

45. R.G. Parr, R.G. Pearson, J. Am. Chem. Soc. 105 (1983) 7512-7516. https://doi.org/10.1021/ja00364a005

46. A. Najiya, C.Y. Panicker, M. Sapnakumari, B. Narayana, B.K. Sarojini, C. Van Alsenoy. Spectrochimica Acta Part A: Molecular and Biomolecular Spectroscopy. 133 (2014) 526-533. DOI: 10.1016/j.saa.2014.06.049

47. J.B. Foresman. In Exploring chemistry with electronic structure methods: a guide to using gaussian. Edited by E. Frisch. Pittsburg, PA. 1996. 